The Mediating Role of Sibling Maintenance Behavior Expectations and Perceptions in the Relationship between Family Communication Patterns and Relationship Satisfaction Resubmitted for consideration to the Journal of Family Communication 


\begin{abstract}
Sibling relationships are influenced both by the behaviors performed within the relationship (e.g., relational work; Myers et al., 2001) and by the family system as a whole (White \& Klein, 2008). This study extends family communication patterns theory (FCP) by examining whether communicative relationship maintenance plays a role in the relationship between FCP and sibling relationship satisfaction. Data from 327 adult siblings from across the United States tested using Hayes (2013) PROCESS revealed that conversation and conformity orientation had positive indirect effects on sibling relationship satisfaction through both (a) relational maintenance expectations and (b) perceptions of sibling actual maintenance behavior in nearly all models (i.e., including positivity, openness, assurances, networks, and tasks maintenance behaviors). The results suggest that the parent-child relationship remains important long after children become adults as it continues to influence interpersonal relationships with others. Future directions for communication scholars are discussed along with theoretical implications for research on family communication patterns and the maintenance strategy framework.
\end{abstract}




\section{The Mediating Role of Sibling Maintenance Behavior Expectations and Perceptions in the Relationship between Family Communication Patterns and Relationship Satisfaction}

All relationships require maintenance in order to remain in a desired state (Dindia, 2003; Stafford \& Canary, 1991). The sibling relationship, which is unique in that it is often ascribed, yet long lasting and important to the individuals involved (Cicirelli, 1991), is no exception. From childhood, siblings serve as confidantes and perform many different supportive roles (Lamb, 2014; White, 2001). Sibling relationships are some of the longest relationships individuals have, thus it is important to understand how they are maintained through ongoing communication. When sibling relationships are maintained, they can be beneficial to both parties. For many, siblings remain sources of support, advice, and companionship throughout adulthood (Lamb, 2014). In fact, two-thirds of adults report that their sibling is their closest friend (White \& Riedmann, 1992). Despite this, little is known about how sibling relationships are maintained during early-to-middle adulthood, or what role family experiences in childhood play in adult sibling relationship maintenance (Mikkelson, 2014). Research on all stages of the adult sibling relationship lifecycle including emerging adulthood (Authors, 2015), middle adulthood (Myers, Brann \& Rittenour, 2008), and late adulthood (Goodboy, Myers, \& Patterson, 2009) has illustrated the positive influence maintenance behavior can have on the sibling relationship: more relationship maintenance has been associated with increases in relationship quality (e.g., relationship satisfaction and closeness).

Maintenance includes specific interpersonal behaviors or strategies that work to sustain a desired relationship status and can include the use of positivity, openness, assurances, sharing tasks, and sharing networks (Canary \& Stafford, 1992; Dindia, 2003). Authors (2015) found that perceptions of a sibling's maintenance behavior tends to be a more significant predictor of 
satisfaction with the sibling relationship than participants' self-reported maintenance behavior. Extending that finding, this study seeks to explore how expectations for maintenance behavior may be associated with the perceptions participants have of their siblings' behaviors and the resulting relationship satisfaction levels.

However, expectations for and behaviors within sibling interactions do not occur inside of a vacuum. According to the systems framework, families are interdependent in that, for example, the interactions between parents and children can influence the interactions among other family members (White \& Klein, 2008). In this study, focus will be placed on participants' family communication patterns (FCP) because FCP establish ideas about how relationships should be, and have been linked to family relationship factors such as satisfaction, functioning, and closeness in extant studies (see Schrodt, Witt, \& Messersmith, 2008). However, FCP research has focused primarily on parent-child relationships. This study aims to understand how FCPs influence sibling relationship factors as well as uncover how the association between FCPs and relationship satisfaction occurs in the sibling relationship by exploring both expectations for and perceptions of sibling maintenance behavior as mediators (see Figure 1). To more fully articulate the proposed mediation model, the relationship maintenance framework will be detailed first, explaining the role of maintenance in sibling relationship satisfaction followed by the relationship between FCP and relationship satisfaction and finally, how relationship maintenance behavior perceptions and expectations may act as a mediator between FCP and relationship satisfaction.

$<$ Figure 1 here $>$

\section{Relationship Maintenance}


According to Dindia (2003), relational maintenance is an interpersonal process. During this process, maintenance strategies are used communicatively to "sustain desired relational definitions" (Canary \& Stafford, 1992, p. 243), such as satisfying and stable relationships. Through exploratory studies on romantic relationships, five maintenance strategies have been identified: (a) positivity, or optimistic and cheerful interactions; (b) openness, or direct discussion of the relationship; (c) assurances, or interactions that stress the importance of the relationship to the individuals involved; (d) social networks, or sharing friends and family; and (e) sharing tasks, or the fair delegation of responsibilities (Stafford \& Canary, 1991).

Although created originally for romantic relationships, the framework has been applied within platonic relationships (e.g., Johnson, 2001; Wright, 2004). Stafford and Canary (1991; Canary, Stafford, Hause, \& Wallace, 1993; Stafford \& Canary, 2006) proposed that differences in maintenance strategy use might exist depending on relationship type (e.g., friends, family, significant others). More recent research has found however that siblings report using much the same relationship maintenance strategies as people in other types of close relationships, though patterns of use varies. For example, Myers and Members of COM 200 (2001) found siblings used (in order) 1) tasks, 2) positivity, and 3) assurances most while Mikkelson (2014) found that adult siblings used 1) positivity, 2) assurances, and 3) tasks most. In addition, Myers (2011) found that people reported maintaining their adult sibling relationships for the following reasons (among others): because we are family, we provide each other with support and we share similar or common interests and experiences. Together, these studies evidence that relationship maintenance behaviors are essential to maintaining sibling relationships, just as they are for other types of relationships. 
Previous research has explored how perceptions of a partner's maintenance strategies are associated with relationship outcomes (e.g., Canary \& Stafford, 1992; Canary, Stafford, \& Semic, 2002; Authors, 2015; Stafford \& Canary, 1991), but has seldom examined the expectations for maintenance behaviors in general. In one study on maintenance expectations, Dainton (2000) assessed the impact of the discrepancy between expectations (i.e., the comparison level) and behaviors on relationship satisfaction in romantic relationships. When Dainton (2000) compared the impact of discrepancies with simple perceptions of partner maintenance use in romantic relationships, results indicated that perceptions were a stronger predictor of satisfaction levels than the discrepancies. However, "expectancy fulfillment for the partner's use of maintenance behaviors accounted for a moderate amount of the variance in satisfaction" (Dainton, 2000, p. 832), which suggests that expectations are important to consider. These expectations may color how participants perceive their sibling's behaviors.

Taking into account the shared history experienced in sibling relationships and the familial environment may change the role of expectations in maintenance behaviors and their influence on relationship satisfaction. Expectations have been defined as "an enduring pattern of anticipated behavior" and can be both individualistic (e.g., based on past relationship history) and societal (Burgoon, 1993, p. 31). Researchers can tailor the question of expectations, asking participants, "What do you expect this sibling to do," which takes into account that a difference might exist between what people may expect overall and for particular people. Other factors like context, relationship, or communicator characteristics are thought to influence the expectations one holds as well (Burgoon, 1993). In a sibling relationship, the family environment may be one such contextual characteristic that influences a person's expectancies. As such, the relationship 
between family communication environment and expectations for sibling maintenance behaviors will be explored in more depth within this study.

\section{Relational Maintenance and Satisfaction}

Relational maintenance behavior has been associated with positive relational outcomes such as satisfaction, commitment, love, and liking (see meta-analysis by Ogolsky \& Bowers, 2013). Sibling use of maintenance specifically has been associated with positive relational outcomes such as love and liking of the sibling as well as communication and relationship satisfaction (Myers, Goodboy, \& Members of COMM 201, 2013; Myers \& Members of COM 200, 2001; Myers \& Weber, 2004). Based on these findings, the following hypothesis is proposed:

H1: Siblings' (a) expected and (b) perceived relational maintenance behaviors will be positively associated with relationship satisfaction.

\section{Family Communication Patterns}

The family and communication therein are locations of early socialization experiences (Vangelisi, 2004). How individuals are socialized to communicate within their families as children will have some effect on their interpersonal interactions for the rest of their lives through the relationship schema they develop at home (Koerner \& Fitzpatrick, 2002). Family Communication Patterns (FCP) theory draws from an earlier two-dimensional model of family communication patterns developed as part of political socialization research (McLeod \& Chaffee, 1972), that was later refined by Koerner and Fitzpatrick in 2002. Koerner and Fitzpatrick (2002) applied the relationship model to a specific context (i.e., the family) and further developed the model by describing two orientations individuals will fall on according to the original co-orientation model. 
Behaviors of families can be placed along two orientations distinguished by FCP theory, conversation and conformity. These orientations are central beliefs that predict how families communicate. Conversation orientation is the degree to which a family encourages open communication about a variety of topics. Conformity orientation is the degree to which a family "stresses a climate of homogeneity of attitudes, values, and beliefs" (Koerner \& Fitzpatrick, 2002, p. 85). Families can range from high to low on both orientations. The orientations can be used to predict how individual family members will respond to certain events and how the family as a whole will cope with and work through problems together. "Family communication patterns not only facilitate family functioning, but ultimately enhance the general health and well-being of individual family members" (Schrodt et al., 2008, p. 265). One phenomena that can serve to enhance the well-being of individual family members is the act of maintaining family relationships.

\section{FCPs and Relationship Satisfaction}

Placing value on open conversations in families has been linked to positive relationship outcomes inside and outside the family. In a meta-analysis of 52 studies, Schrodt et al. (2008) found that across studies, conversation orientation was strongly related to psychosocial outcomes such as relationship satisfaction, closeness, relational commitment, physical and mental health, and self-esteem (more so than conformity orientation). Punyanunt-Carter (2008) found that in father-daughter dyads, conversation orientation was associated with father and daughter communication satisfaction while conformity orientation's relationship was not significant. Samek and Rueter (2011) examined the outcomes of FCP on the sibling relationship specifically. They found that families that were high in both conversation and conformity orientation had the closest adolescent siblings. Families low in conformity and conversation orientation had the least 
close siblings. While closeness is not the same as relationship satisfaction, Roberts (2003) found that people with close long distance romantic relationships (i.e., those with high interdependence) tended to report higher relationship satisfaction. Sibling and romantic relationships are certainly distinct, yet similarities can be drawn as many sibling relationships are also long distance.

Baxter and Pederson (2013) recognized the limited existing work on relationship satisfaction and FCP and proposed that Koerner and Fitzpatrick's (2006) theorizing that there is no single ideal family communication pattern may have contributed to few researchers examining this association. Because little research has examined FCPs association with relationship satisfaction, the following predictions are limited to the two dimensions delineated by FCP theory: conversation and conformity (i.e., rather than make predictions about all four family types). This is common in FCP work where foundational research is needed (e.g., cultural differences in Dorrance Hall et al., in press). Based on what little is known, families high in conversation and conformity orientation should have more satisfactory sibling relationships than families low in conversation and conformity orientation.

$\mathrm{H} 2$ : Conversation orientation will be positively associated with sibling relationship satisfaction.

H3: Conformity orientation will be positively associated with sibling relationship satisfaction.

\section{FCP and Relational Maintenance}

FCP contribute to relationship schema (i.e., ideas about prototypical interaction; Koerner \& Fitzpatrick, 2002; Ledbetter \& Beck, 2014) which provide "baseline expectations" for how family members will communicate (Baxter \& Pederson, 2013, p. 133). Relationship schema also 
set expectations for maintenance in family relationships, and provide cognitive depictions of what relationships should look like or how siblings, for example, should act toward one another. Family relationship schema include the communicative behaviors expected to maintain those relationships. The relationship maintenance behavior framework assumes that conversations are used to keep relationships in a desirable state. Depending on the family environment in which a person grew up, which influenced the relationship schema $\mathrm{s} /$ he developed, $\mathrm{s} / \mathrm{he}$ may be more or less likely to value or expect given maintenance behaviors.

Openness provides a direct example of how a family environment marked by high conversation orientation may influence a person's perceptions of openness as a marker of a satisfactory relationship since a major tenant of openness is engaging in conversation. Assurances places a similar emphasis on communication (e.g., keeping an upbeat tone, expressing love to others). In fact, Schrodt, Ledbetter, and Ohrt (2007) found that conversation orientation is positively associated with affection (i.e., expression of warmth and love) in the parent-child relationship. Conversation orientation is likely related to higher use of positivity as children of high conversation orientation families are encouraged to express their feelings, both positive and negative. It is also likely that siblings from high conversation orientation families have more overlap in their social networks. Children in high conversation families likely have larger, more diverse networks due to openness to different ideas. They might also be more likely to share the friends with their siblings and invite them to family gatherings because these families are marked by frequent and spontaneous interaction with one another (Fitzpatrick, 2004). Finally, siblings in high conversation orientation families likely negotiate their task responsibilities openly and often which may lead to higher use of task maintenance behaviors. 
H4: Conversation orientation will be positively associated with siblings' (a) expected and (b) perceived relational maintenance behaviors (i.e., positivity, assurances, openness, social networks, and tasks).

The role of conformity orientation in maintenance perceptions and expectations, and how it in turn relates to relationship satisfaction is less straightforward. Past research on conformity orientation suggests that people from high conformity families exhibit decreased interpersonal skill (Koesten, 2004) as "conformity orientation inhibits skill development" (Ledbetter, 2009, p. 133). Inhibited interpersonal skill is proposed to generally decrease the frequency of maintenance strategy use in relationships (which Ledbetter found support for in face-to-face communication between friends).

Specifically, families high in conformity orientation limit the range of acceptable attitudes, beliefs, and values for family members, therefore siblings in high conformity families likely express less openness with one another. Supporting this rationale, Bridge and Schrodt (2013) found that young adults from high conformity orientation families had higher preferences for privacy (e.g., wanting to be alone, respect for lack of self-disclosure). In regard to assurances, siblings from high conformity orientation families are less likely to affirm their commitment to the relationship perhaps because their commitment to one another is unspoken. Obedience to parents is stressed in high conformity orientation families (Koerner \& Fitzpatrick, 2002) which likely lends itself to loyalty and obedience to the sibling relationship as well. Supporting this notion, Schrodt et al. (2007) found that parents in high conformity orientation families were less likely to express affection to their children than those in low conformity orientation families. The maintenance strategy of positivity is likely invoked frequently in high conformity families because of the importance placed on harmony in family relationships (e.g., 
avoiding conflict and disagreement). Siblings from high conformity orientation families may have less overlap in their social networks. Children in high conformity families might be less likely to share friends with their siblings and invite them to family gatherings if family expectations mandate strict family-only time. Finally, high conformity orientation may lead to siblings more equally sharing tasks and upholding their task sharing arrangements due to stricter family rules and obligations.

Families that value conformity likely have clear expectations for how family members will maintain their relationships. When these expectations are not met by actual behavior, the consequences may be more extreme in families with higher conformity orientation than in families with lower conformity orientation. This distinction highlights the need to measure both perceptions and expectations. Based on FCP theory, the maintenance behavior framework, and the literature reviewed above, the following relationships are posited:

H5: Conformity orientation will be negatively associated with siblings' (a) expected and (b) perceived assurances, openness, and social networks relational maintenance behaviors and positively associated with siblings' (a) expected and (b) perceived positivity and tasks relational maintenance behaviors.

\section{Relationship Maintenance as a Mediator}

Relationship maintenance provides a communicative explanation of how the relationship between FCP and satisfaction works. Two studies lend evidence to the prediction that relationship maintenance likely mediates the relationship between FCP and sibling relationship satisfaction. First, Ledbetter and Beck (2014) found that relationship maintenance was a significant mediator in the relationship between FCP and the inclusion of the other in the self (IOS) and found that both conversation and conformity orientations predicted relational 
maintenance behaviors between parents and children, which in turn effected IOS. Their study extended FCP theory by illuminating maintenance as a communication process that explains how family schema such as conversation and conformity orientation influence psychological processes. This study further extends FCP theory by bolstering this claim and examining whether communicative relationship maintenance plays a role in the relationship between FCP and sibling relationship satisfaction.

Ledbetter (2009) tested a model similar to this study's proposed model examining the mediating role of online and face to face maintenance behaviors performed by young adults in the relationship between FCP and friendship closeness. Ledbetter found that relational maintenance behaviors fully mediated the relationship between FCP and relationship closeness in young adult friendships, yet this relationship has yet to be explored in sibling relationships. Furthermore, research on maintenance behavior has found that what the other relationship partners are doing has some bearing on relational outcomes. For instance, Authors (2015) recently established a link between the maintenance behaviors participants perceived their siblings doing and higher sibling relationship satisfaction. A goal of this study is to extend previous research by exploring how both the expected and perceived maintenance behaviors of a person's sibling may mediate the relationship between FCP and relationship satisfaction (see Figure 1).

While Ledbetter's (2009) study lends strength to the above predictions, the current study's model is distinct from his in that it tests the role of perceived and expected maintenance behaviors in a sibling relationship. Moreover, past research on expectations has emphasized how individuals' expectations frame relational interactions and people change their communicative actions based on the confirmation and violation of expectations (e.g., Burgoon, 1993). As such, 
this model proposes a causal order whereby FCP orientations shape sibling maintenance expectations. These expectations, in turn, color the interpretation and perception of sibling maintenance behavior. The confirmation or violation of the expectations then shapes individuals' satisfaction within their sibling relationships. For example, if people grow up in an environment that values openness, they believe their siblings will be open within the relationship, but if their siblings fail to meet those expectations, relationship satisfaction may decrease. Therefore, conversation and conformity orientations should be associated with relationship satisfaction indirectly through expectations for sibling maintenance behavior and the resulting perceptions of sibling maintenance behavior (see Figure 1):

H6: Siblings' (a) expected and (b) perceived relational maintenance behaviors will mediate the relationship between FCPs and sibling relationship satisfaction.

\section{Method}

\section{Participants}

To reach a wide variety of demographics, 327 participants $(62.7 \%$ female, $37.3 \%$ male $)$ were recruited using convenience sampling through Amazon mTurk. Amazon mTurk is an online system for collecting data from diverse samples and has been found to be a reliable tool for data collection comparable to traditional samples (see Goodman, Cryder \& Cheema, 2012). About 78.6\% $(n=257)$ of participants were White, $8.9 \%(n=29)$ were African American/Black, 4.6\% $(n=15)$ were Asian/Pacific Islander, 3.1\% $(n=10)$ were Latino, and about $1 \%$ selected American Indian/Alaskan Native $(n=3)$ or South East Asian $(n=4)$. Two percent of participants chose not to disclose their ethnicity and .6\% $(n=2)$ chose other. The mean age of participants was $30.76(S D=11.52)$ and ranged from 18 to 71 . Participants had an average of 2.49 siblings $(S D=2.43)$, with $40.4 \%$ reporting 1 sibling and $26.6 \%$ reporting 2 
siblings. Most participants were first born $(47.1 \%, n=154)$, followed by second born $(33.6 \%, n$ $=110)$.

Demographic information about the participant's sibling was also collected. Just over half (52.9\%) of participants reported on a male sibling $(n=173)$ and $47.1 \%$ reported on female siblings $(n=154)$. Over half $(52.3 \%)$ of participants reported on a sibling of their same sex ( $n=$ $171)$ and $47.7 \%(n=156)$ reported on an opposite sex sibling. Most siblings were fully biologically related (i.e., same mom and dad; $84.4 \%, N=276$ ), followed by partial-biologically related $(11.6 \%, n=38)$ and step-siblings $(2.1 \%, n=7)$, adopted siblings $(1.5 \%, n=6)$ and finally not genetically or legally related, but still considered siblings $(.3 \%, n=1)$. Siblings' mean age was $28.57(S D=14.26)$. The relative age difference between siblings was $5.17(S D=2.99)$ years. Nearly half of participants $(48.6 \%, n=159)$ lived more than 91 miles away from their sibling while only 60 participants were currently living with their sibling. ${ }^{1}$

\section{Procedures}

Participants who were over 18-years old and had at least one sibling answered a 20 minute survey hosted on Qualtrics. Participants were asked to choose the sibling whose birthday (month/day) is closest to theirs at the beginning of the survey and were instructed to focus only on the chosen sibling for the questions that followed (Myers et al., 2008). The term sibling was flexible and could refer to adopted, step, biological, and other people participants considered siblings.

\section{Measures}

Family Communication Patterns. The Revised Family Communication Patterns (RFCP, Ritchie \& Fitzpatrick, 1990) scale consists of two subscales: an 11-item conformity

\footnotetext{
${ }^{1}$ Independent samples t-tests were conducted to compare siblings who lived together versus apart. The two groups did not significantly differ on any of the study variables except for ratings of relationship satisfaction $\left(\mathrm{M}_{\text {together }}=\right.$ $\left.4.77, \mathrm{SD}=1.40, \mathrm{M}_{\text {apart }}=5.19, \mathrm{SD}=1.47 ; \mathrm{t}(321)=-2.01, p=.046, d=.29\right)$.
} 
orientation scale (e.g., "When anything really important is involved, my parents expect me to obey without question.”) and a 15-item conversation orientation scale (e.g., "In our family, we often talk about topics like politics and religion where some persons disagree with others."). The 26 total items were measured using a 7-point Likert-type scale ranging from strongly disagree (1) to strongly agree (7). Both the conversation orientation $(\alpha=.95, M=4.43, S D=1.40)$ and conformity orientation $(\alpha=.89, M=4.08, S D=1.29)$ subscales showed high reliability.

Relationship Maintenance Behaviors. The 29-item Relational Maintenance Strategy Measure (RMSM; Canary \& Stafford, 1992) was modified to evaluate the participants’ maintenance strategies and their perceptions of their sibling's maintenance strategy use. Two items, "show myself to be faithful to him/her" and "try to be romantic, fun, and interesting with him/her" were altered such that the word "faithful" was changed to "reliable" and the word "romantic" was removed. Additionally, the words "I" or "my sibling" were added to the beginning of each item stem. The 29-items were measured using a 7-point Likert-type scale ranging from strongly disagree (1) to strongly agree (7). The measure includes subscales for positivity (e.g., "I attempt to make our interactions very enjoyable"), openness (e.g., "I encourage my sibling to disclose thoughts and feelings to me"), assurances (e.g., "I show my love for my sibling"), networks (e.g., "I like to spend time with our same friends"), and tasks (e.g., "I help equally with tasks that need to be done").

Participants filled out the measure twice: once for their expectations of their sibling's behavior and once for their perceptions of their sibling's behavior. When assessing the sibling's behaviors, they were told to "please indicate: (a) the extent to which you expect your sibling should do the following to maintain your sibling relationship and (b) the extent to which each of the following describes how your sibling maintains your relationship." The individual subscales 
showed high reliability for both expectations for and perceptions of sibling maintenance behavior (see Table 1 for Cronbach's alphas, means, and standard deviations for expected and perceived sibling maintenance).

$$
<\text { Table } 1 \text { here }>
$$

Relationship Satisfaction. The Relationship Assessment Scale (RAS; Hendrick, 1988) was modified to ask about sibling relationships. Specifically, "sibling” was substituted for "partner" and the question format was changed to statements so that the same scale anchors could be used (e.g., "how well does your partner meet your needs?' was changed to 'my sibling meets my needs."). Other example items included "I am satisfied with my sibling relationship," and "I have a lot of problems in my relationship with this sibling," reverse coded. Items were measured on a 7-point Likert-type scale with anchors ranging from strongly disagree (1) to strongly agree (7). Cronbach's alpha for the seven-item scale was $.90(M=5.11, S D=1.46)$.

\section{Results}

\section{Preliminary Analysis}

Before serial multiple mediation models were tested, all variables were tested for correlation (see Table 2). Conversation orientation was positively related to all expected and all perceived sibling maintenance behaviors and relationship satisfaction. Conformity was positively related with expectations for sibling openness and negatively related to relationship satisfaction. All expected and perceived sibling maintenance behaviors were positively associated with relationship satisfaction. ${ }^{2}$ Additionally, a series of paired t-tests were conducted to assess the differences between expected and perceived sibling maintenance behaviors. In all five

\footnotetext{
${ }^{2}$ Participant sex and age as well as sibling sex and age exhibited some correlations with either the dependent, mediation, or control variables. As such, they were included as covariates in the serial mediation models.
} 
maintenance behaviors, participants held significantly higher expectations for their siblings' maintenance behaviors than they perceived their siblings actually performing (see Table 1).

$$
<\text { Table } 2 \text { here }>
$$

\section{The Mediation Models}

To analyze the proposed relationship, two serial mediation models were tested using Hayes' PROCESS macro for SPSS for each maintenance strategy (Hayes, 2013). The first set of models had conversation orientation as the independent variable and controlled for conformity orientation, whereas the second set of models had conformity as the independent variable and controlled for conversation orientation. ${ }^{3}$ The resulting models predicted between $32-62 \%$ of the variance of relationship satisfaction depending on the maintenance strategy being assessed. All regression coefficients are reported as unstandardized betas. See Table 3 for the $\mathrm{R}^{2}$ of relationship satisfaction, direct, and indirect effect results.

$$
<\text { Table } 3 \text { here }>
$$

Maintenance Behaviors and Relationship Satisfaction. Siblings' expected (H1a) and perceived $(\mathrm{H} 1 \mathrm{~b})$ relational maintenance behaviors were expected to be positively associated with relationship satisfaction, which was supported by initial correlation analysis. When the full models were tested, relationship satisfaction was not significantly associated with expectations for four of the five individual maintenance strategies (i.e., positivity, assurances, networks, and tasks). Expectations for sibling openness was negatively associated with relationship satisfaction when all other variables were included in the model, $b=-.16, S E=.06, p<.01$. Even though openness was significantly associated with relationship satisfaction, it was opposite than predicted. H1a was not supported (see Table 3, path $b_{1}$ ).

\footnotetext{
${ }^{3}$ Because FCP research also looks at the interaction between conversation and conformity orientations, models were also tested with a conversation and conformity interaction term as a covariate. The interaction term was not significant in any model tested, thus it was not included in the results or discussion.
} 
Relationship satisfaction was positively associated with perceptions of all five sibling maintenance behaviors (see Table 3, path $b_{2}$ ); therefore, H1b was supported.

FCP and Relationship Satisfaction. The second and third hypotheses predicted the relationships between the two FCP orientations and relationship satisfaction. Both conversation (H2) and conformity orientations (H3) were posited to be positively associated with relationship satisfaction. Initial correlation analysis supported $\mathrm{H} 2$ but not $\mathrm{H} 3$ (conformity orientation was negatively associated with satisfaction; see Table 2). However, when the mediating and control variables were included in each of the five maintenance strategy models, conformity orientation was never significantly associated with relationship satisfaction, and conversation orientation was not significantly associated with relationship satisfaction in three (i.e., positivity, assurances, and networks) models. In the models where openness and tasks were included as mediators, a significant, positive association between conversation and relationship satisfaction was found, as was predicted in $\mathrm{H} 2$ (see Table 3, path c'). Given that conversation was not significantly associated with relationship satisfaction in three of the five models, though, H2 was generally not supported. When any of the relationship maintenance strategies were included in the model, the direct effect ceased being significant; therefore, H3 was not supported.

FCP and Maintenance Behaviors. The next hypotheses examined the relationships among the FCP dimensions and both expected and perceived maintenance behavior. Positive associations were predicted between conversation and both expected (H4a) and perceived (H4b) sibling maintenance behaviors. Initial correlation analyses indicated that conversation was associated with both expected and perceived maintenance behaviors, supporting H4a-b. Conformity orientation was predicted to have a negative association with expected (H5a) and perceived (H5b) openness, assurances, and social networks, and a positive association with 
positivity and tasks. Initial correlation analysis did not support H5a-b. In fact, conformity orientation was seldom significantly related to any maintenance behavior but was positively associated with openness (opposite of what was predicted; see Table 2). Yet when the full model was assessed, conversation orientation was significantly and positively associated with both expectations for, and perceptions of all five sibling maintenance behaviors, as was predicted in H4a and H4b (see Table 3, path $a_{1}$ and path $a_{2}$ ).

Conformity orientation was significantly and positively associated with overall expectations for each of the five sibling maintenance behaviors, partially supporting H5a (see Table 3, path $a_{1}$ ). Conformity was not however significantly associated with perceptions of any of the five sibling maintenance behaviors, thus H5b was not supported (see Table 3, path $a_{2}$ ).

Mediation Results. The final hypothesis posited that the relationship between FCP orientations and relationship satisfaction would be mediated by both expected (H6a) and perceived (H6b) sibling maintenance behaviors. The PROCESS macro assessed three possible indirect relationships between the FCP dimension and relationship satisfaction: 1) through expectations for maintenance behaviors $\left.\left(a_{1} b_{1}\right), 2\right)$ through expectations and perceptions $\left(a_{1} d_{1}\right.$ $\left.\left.b_{2}\right), 3\right)$ through perceptions of maintenance behaviors $\left(a_{2} b_{2}\right)$.

In the conversation orientation model, two indirect relationships were significant for all models tested. A significant, positive indirect relationship between conversation and relationship satisfaction through perceived sibling maintenance behaviors was found for all five maintenance strategies (Table 4). Conversation orientation was positively associated with each perceived maintenance behavior, which in turn was positively associated with relationship satisfaction. 
The second significant indirect relationship was the positive association between the conversation dimension and relationship satisfaction through both expectations for and perceptions of each of the five sibling maintenance behaviors $\left(a_{1} d_{l} b_{2}\right)$, First, higher conversation orientation was associated with greater expectations for maintenance behavior. Second, higher expectations were associated with higher ratings of perceived maintenance behavior. Finally, perceiving more maintenance behavior was associated with higher ratings of relationship satisfaction (Table 4).

When assessing conformity orientation as the independent variable, one indirect relationship was significant for four of the five models tested. Conformity orientation was indirectly positively associated with relationship satisfaction through both expectations for and perceptions of all maintenance behaviors except for networks $\left(a_{1} d_{1} b_{2}\right)$. First, higher conformity orientation was associated with greater expectations for four of the five maintenance behaviors. Second, higher expectations of maintenance were associated with higher perceived maintenance behavior. Finally, perceiving more of each maintenance behavior (i.e., for all behaviors except networks) was associated with higher ratings of relationship satisfaction (Table 4). The indirect association between conformity orientation and satisfaction through perceived maintenance behavior $\left(a_{1} b_{l}\right)$ was not significant for any model tested.

Openness was the only maintenance strategy where a significantly negative indirect relationship between conversation orientation and satisfaction through expected maintenance behavior emerged $\left(a_{1} b_{1}\right), b=-.05, S E=.03,95 \%$ CI [-.11 - -.01]. In this case, higher reported conversation orientation was associated with higher expectations for openness, but higher expected openness was associated with less relationship satisfaction. Therefore, higher conversation orientation indirectly reduced satisfaction through expectations for openness. 
Likewise, openness was the only maintenance strategy where a significant indirect effect between conformity and satisfaction through expected maintenance behavior was found $\left(a_{1} b_{1}\right), b$ $=-.04, S E=.02,95 \%$ CI [-.10 - -.01]. Again, the relationship between FCP orientation and satisfaction through expectations for openness was negative. When this pattern is taken alone, it might indicate that if openness expectations are not met, siblings feel less satisfied with their relationships. However, there is a high association, $b=.42, S E=.06, p<.001$, between expectations for and perceptions of openness behaviors. If siblings hold high expectations for openness and these expectations are met (which they tend to be), then the overall indirect effect on relationship satisfaction is positive. This pattern suggests that it is important to look at both expected and perceived maintenance behaviors.

Summary. Although the indirect relationship between both FCP dimensions and relationship satisfaction through only expectations tended to be nonsignificant, results generally supported the proposed model (Figure 1) where both expectations for and perceptions of sibling maintenance behavior acted as mediators. The inclusion of expected and perceived maintenance behavior mediated all of the models tested aside from one (conformity and networks). As such, H6a and H6b were ultimately supported.

\section{Discussion}

Family communication patterns (FCP) capture the processes family members use to create a shared social reality (Koerner \& Fitzpatrick, 2002). The way they achieve this shared reality (through conversation or conformity orientation, or both) has implications for their communication behaviors and their relationship satisfaction. This study examined how these processes occur by exploring the mediating effect of maintenance behavior expectations and perceptions in the sibling relationship. Conversation and conformity orientation had positive 
indirect effects on sibling relationship satisfaction through both expectations for and perceptions of sibling relational maintenance behavior in all models tested aside from one (i.e., conformity and networks). Based on these findings, the parent-child communication environment remains important long after children have grown and moved out of the childhood home as it continues to influence interpersonal relationships with others. Patterns of findings are discussed in more detail below followed by theoretical implications of this research.

In line with what was predicted based on FCP theory, conversation orientation was associated with higher expectations for maintenance behavior and more perceived behavior across all models. This pattern of findings indicates that siblings from high conversation oriented families where all members are encouraged to speak freely and frequently about diverse opinions (Koerner \& Fitzpatrick, 2003) expect their siblings to exhibit more openness and positivity, share tasks, be part of the same network of friends, and express their love and commitment to the relationship. It makes sense that these siblings would expect and perform a lot of maintenance behaviors based on the way they were socialized to act with one another.

Conformity was also associated with higher expectations, but was not associated with perceived maintenance behavior. High conformity orientation families are marked by sharing similar attitudes, values, and beliefs. Because they hold views that interactions should be harmonious and that children should respect their elders (Koerner \& Fitzpatrick, 2002), members of high conformity families typically avoid talking about dissonant views in order to avert any conflict, instead communicating about shared beliefs and interests (Koerner \& Fitzpatrick, 1997; Shearman \& Dumlao, 2008). The emphasis on interdependence, harmony, and conflict avoidance in high conformity oriented families may explain why siblings from high conformity orientation families hold higher expectations for all maintenance behaviors than those with low 
conformity orientation. For example, believing that all encounters should be harmonious is congruent with the basis for positivity - that relational partners attempt to be upbeat and positive in their interactions. Similarly, higher conformity does not mean that families do not talk to each other. Instead, members of these families may avoid expressing contradictory views. The results of this study suggest that high conformity families still expect siblings to be open with one another and assure one another about one's investment in the relationship. Furthermore, the interdependence associated with higher conformity may explain why participants had higher network and task expectations for their siblings. Despite holding these expectations, conformity orientation was not associated with actual perceived maintenance behavior. The combination of conformity orientation and holding high expectations in the parent-child relationship has been associated with negative outcomes such as suicide ideation among young adults (Miller \& Day, 2002). Future research should further explore the influence of high conformity orientation and sibling expectations on the sibling relationship as research on conformity orientation among siblings is still in its infancy.

As predicted, higher perceptions of maintenance behavior alone were associated with higher relationship satisfaction. This relationship is complicated by the family communication environment in which the siblings grew up and the expectations they hold for maintenance behavior in their relationship. Expectations and perceptions of maintenance behaviors mediated the relationship between both conversation and conformity orientation and relationship satisfaction. This means that participants from families that were high in either conversation or conformity orientation had higher expectations for their siblings' maintenance behaviors which were associated with higher perceptions of their actual maintenance behavior, which then led to higher sibling relationship satisfaction. 


\section{Theoretical Implications}

Despite decades of theoretical interest in linking FCP with positive relationship outcomes (Schrodt et al., 2008), scholars have just begun to explore potential mediating processes that explain how FCP impact relational behaviors and outcomes (e.g., Schrodt \& Ledbetter, 2007; Schrodt et al., 2007). This study was not the first to explore relationship maintenance behaviors as mediators in the FCP and relational outcomes association. However, unlike Ledbetter and Beck (2014) who looked at relationship maintenance behaviors in parent-child relationships and Ledbetter (2009) who looked at relationship maintenance behaviors in friendships, this study explored the sibling relationship — a relationship embedded within the larger family system. The conversation and conformity behaviors enacted and endorsed within the parent-child relationships were associated with the expected and perceived relational maintenance behaviors of siblings. It is important to note that the average age of participants was around 30 and only $18 \%$ of participants currently lived with their sibling. In other words, the influence of the parentchild dynamic reached beyond individuals who were still living in the same household and into participants' adult relationship dynamics. Future research needs to continue to explore how the patterns established in childhood and adolescence reach into adulthood.

The pattern of results found in this study suggests that it is not enough to only look at perceived relationship maintenance behavior; expectations, like Dainton (2000) also found, contribute to the relational outcomes as well. According to Koerner and Fitzpatrick (2003), "the same behavior can have different outcomes depending on the communication context in which it occurs" (p. 192). The family communication environment in which the sibling pair was socialized bears greatly on what they see as normative and expected in terms of relationship maintenance behaviors. Having high expectations for a siblings' maintenance behavior in this 
study was generally not a negative. Specifically, expectations for maintenance behavior alone were not associated with relationship satisfaction except for when considering openness.

Expectations did, however, play an important role in the relationship between both conversation and conformity orientation when both perceptions and expectations for maintenance behavior were in the model. This suggests that the positive relationship between family environments high in conversation and conformity orientation and the relationship satisfaction experienced between siblings occurs through the sibling's high expectations for maintenance behavior as well as the perceptions of those behaviors. Siblings who hold high expectations and perceive that their sibling performs a lot of maintenance reap rewards based on their socialization grounded in their family communication environment.

Furthermore, only one model found no indirect effects (conformity and networks). In all other models, the addition of expected and perceived relationship maintenance mediated the association between conversation/conformity and relationship satisfaction. Not only did the addition of these variables change the relationship between FCP orientation and satisfaction, in the case of conformity, it shifted the orientation. In the correlation analysis (Table 2), conformity was negatively associated with satisfaction; however, the indirect relationships were primarily positive (Table 4). This shift showcases the complex ways in which the family environment shape sibling relationship satisfaction. The proposed model is only one process by which FCP are associated with relationship satisfaction in the sibling relationship, but is a start to understanding how the larger family system plays a role in the adult sibling dynamics.

\section{Limitations and Directions for Future Research}

Although the study contributes to the literature through its focus on the sibling relationship, the non-college aged sample, and the inclusion of both expected and perceived maintenance behavior, limitations should be acknowledged. First, cross-sectional data limits the 
predictive utility of the findings, however, FCP are considered a relatively stable set of indicators for family environment (i.e., FCP likely does not change easily over time, especially in adulthood). As a result, it is reasonable to postulate that FCP comes before current expectations and perceptions of maintenance behavior as well as before participants' current levels of relationship satisfaction with their siblings. Additionally, expectations were proposed to precede perceptions of maintenance behavior yet it is possible that the perceived maintenance behaviors of siblings contributed to expectations held for maintenance behavior. A longitudinal design would help verify the causal order of the mediation model tested in this study.

Second, dyadic data should be collected in order to compare viewpoints of FCP and maintenance behaviors and expectations between siblings to identify potential discrepancies in perceptions. Third, all participants were recruited from Amazon mTurk. While some scholars have claimed that mTurk is a reliable and valuable data collection tool (for example, see Goodman et al., 2012), others are wary of whether participant responses accurately represent the average person. This limitation should be considered when interpreting this study's findings.

Theoretically, it is important to note that the RMSM itself is not without criticism. Stafford (2011) noted that the items themselves can be double or triple barreled and many contain qualifiers like "very" that can distort responses. Despite these criticisms, the RMSM is a widely used measure (e.g., Ogolsky \& Bowers, 2012) and showed high reliability with this population (Table 2). Using the RMSM allows for greater generalization and comparison of results across multiple studies testing different types of relationships. The ability to compare results to existing patterns was important in the creation of this study; however, future research may instead choose to use Stafford's (2011) updated version of the relationship maintenance behavior scale to assess relational maintenance behaviors. 
Finally, relationship prototypes or expectations (i.e., mental guides for what relationships should be like; Baxter \& Wilmot, 1984) are derived from a variety of places, FCPs being one of them. Future research could explore other factors that might influence the expectations of sibling maintenance behaviors. For instance, past patterns of sibling maintenance behavior may influence future expectation. Additionally, the media may foster unrealistic expectations for sibling maintenance behavior. Past research has found that the media often portrays unrealistic relationship scenarios, which can result in inflated expectations for those relationships in real life (e.g., Brown, Steele, \& Walsh-Childers, 2002). Media effects research has seldom focused on how the media influences sibling relationship prototypes, but it is reasonable to hypothesize that media portrayals of sibling relationships may influence the expectations people have for their siblings. In addition to the family environment participants are embedded within, future research should explore how both direct (e.g., prior experience) and indirect (e.g., mediated) experience influence the sibling dynamic.

\section{Conclusion}

Extending previous research that has identified the importance of relationship maintenance behaviors in sibling relationship satisfaction, this study explored the process of how family communication patterns are associated with sibling relationship satisfaction. The findings indicate that expectations and perceptions of sibling maintenance behavior partially, if not fully, explain the association between FCP and relationship satisfaction. How participants expected their siblings to behave along with their perceptions of that behavior mediated the relationship between both conversation and conformity orientation and sibling relationship satisfaction. Conformity and conversation orientation contributed to higher sibling relationship satisfaction through the mediators. Future research should longitudinally examine the ways in relationship maintenance behaviors play a role in the association between FCP and relationship outcomes 
including how sibling maintenance behaviors (i.e., normative expectations, types, and amount) change over the course of adulthood. 


\section{References}

Authors. (2105). Blinded for review.

Baxter, L. A., \& Pederson, J. R. (2013). Perceived and ideal family communication patterns and family satisfaction for parents and their college-aged children. Journal of Family Communication, 13, 132-149. doi: 10.1080/15267431.2013.768250

Baxter, L. A., \& Wilmot, W. W. (1984). Secret tests. Human Communication Research, 11, 171201. doi: 10.1111/j.1468-2958.1984.tb00044.x

Bridge, M. C., \& Schrodt, P. (2013). Privacy orientations as a function of family communication patterns. Communication Reports, 26, 1-12. doi: 10.1080/08934215.2013.773054

Brown, J., Steele, J., \& Walsh-Childers, K. (2002). Sexual teens. In Sexual media: Investigating media's influences on adolescent sexuality. Mahwah, NJ: Erlbaum.

Burgoon, J. K. (1993). Interpersonal expectations, expectancy violations, and emotional communication. Journal of Language and Social Psychology, 12, 30-48. doi: $10.1177 / 0261927 X 93121003$

Canary, D. J., \& Stafford, L. (1992). Relational maintenance strategies and equity in marriage. Communication Monographs, 59, 243-267. doi: 10.1080/03637759209376268

Canary, D. J., Stafford, L., Hause, K., \& Wallace, L. (1993). An inductive analysis of relational maintenance strategies: A comparison among lovers, relatives, friends, and others. Communication Research Reports, 10, 5-14. doi: 10.1080/08824099309359913

Canary, D. J., Stafford, L., \& Semic, B. A. (2002). A panel study of the associations between maintenance strategies and relational characteristics. Journal of Marriage and Family, 64, 395-406. doi: 10.1111/j.1741-3737.2002.00395.x

Cicirelli, V. G. (1991). Sibling relationships in adulthood. Marriage and Family Review, 16, 291-310. doi: 10.1300/J002v16n03_05 
Dainton, M. (2000). Maintenance behaviors, expectations for maintenance, and satisfaction: Linking comparison levels to relational maintenance strategies. Journal of Social and Personal Relationships, 17, 827-842. doi: 10.1177/0265407500176007

Dindia, K. (2003). Definitions and perspectives on relational maintenance communication. In D. J. Canary \& M. Dainton (Eds.), Maintaining relationships through communication: Relational, contextual, and cultural variations. Mahwah, NJ: Lawrence Erlbaum.

Dorrance Hall, E., McNallie, J., Custers, K., Timmermans, E., Wilson, S., \& Van den Bulck, J. (in press). A cross-cultural examination of the mediated role of social support and talking with parents on the relationship between family communication patterns and first-year college student academic and social adjustment in the United States and Belgium. Communication Research.

Fitzpatrick, M. A. (2004). Family communication patterns theory: Observations on its development and application. Journal of Family Communication, 4, 167-179. doi: $10.1080 / 15267431.2004 .9670129$

Goodboy, A. K., Myers, S. A., \& Patterson, B. R. (2009). Investigating elderly sibling types, relational maintenance, and lifespan affect, cognition, and behavior. Atlantic Journal of Communication, 17, 140-148. doi: 10.1080/15456870903024852

Goodman, J. K., Cryder, C. E., \& Cheema, A. (2012). Data collection in a flat world: The strengths and weaknesses of Mechanical Turk samples. Journal of Behavioral Decision Making, 26, 213-224. doi: 10.1002/bdm.1753

Hayes, A. F. (2013). Introduction to mediation, moderation, and conditional process analysis: A regression-based approach. New York, NY: Guilford. 
Hendrick, S. S. (1988). A generic measure of relationship satisfaction. Journal of Marriage and the Family, 50, 93-98. doi: 10.2307/352430

Johnson, A. (2001). Examining the maintenance of friendships: Are there differences between geographically close and long-distance friends? Communication Quarterly, 49, 424-435. doi: $10.1080 / 01463370109385639$

Koerner, A. F., \& Fitzpatrick, M. A. (1997). Family type and conflict: The impact of conversation orientation and conformity orientation on conflict in the family. Communication Studies, 48, 59-75. doi: 10.1080/10510979709368491

Koerner, A. F., \& Fitzpatrick, M. (2002). Toward a theory of family communication. Communication Theory, 12, 70-91. doi: 10.1111/j.1468-2885.2002.tb00260.x

Koerner, A. F., \& Fitzpatrick, M. (2003). Communication in intact families. In A. L. Vangelisti (Ed.), Handbook of family communication (pp. 159-183). Mahwah, NJ: Lawrence Erlbaum.

Koerner, A. F., \& Fitzpatrick, M. A. (2006). Family communication patterns theory: A social cognitive approach. In D.O. Braithwaite \& L.A. Baxter (Eds.), Engaging theories in family communication: Multiple perspectives (pp. 50-65). Thousand Oaks, CA: Sage.

Koesten, J. (2004). Family communication patterns, sex of subject, and communication competence. Communication Monographs, 71, 226-244. doi:

$10.1080 / 0363775052000343417$

Lamb, M. E. (2014). Sibling relationships across the lifespan: An overview and introduction. In M. E. Lamb \& Sutton-Smith, B. (Eds.), Sibling relationships: Their nature and significance across the lifespan (pp. 1-11). New York, NY: Psychology Press. 
Ledbetter, A. M. (2009). Family communication patterns and relational maintenance behavior: Direct and mediated associations with friendship closeness. Human Communication Research, 35, 130-147. doi: 10.1111/j.1468-2958.2008.01341.x

Ledbetter, A. M., \& Beck, S. J. (2014). A theoretical comparison of relational maintenance and closeness as mediators of family communication patterns in parent-child relationships. Journal of Family Communication, 14, 230-252. doi:

$10.1080 / 15267431.2014 .908196$

McLeod, J. M., \& Chaffee, S. H. (1972). The construction of social reality. In J. T. Tedeschi (Ed.), The social influence processes. Chicago, IL: Aldine Atherton.

Mikkelson, A. C. (2014). Adult sibling relationships. In K. Floyd \& M. T. Morman (Eds.), Widening the family circle: New research on family communication (pp. 19-34). Los Angeles, CA: Sage.

Miller, M., \& Day, L. E. (2002). Family communication, maternal and paternal expectations, and college students' suicidality. The Journal of Family Communication, 2, 167-184.

Myers, S. A., Brann, M., \& Rittenour, C. E. (2008). Interpersonal communication motives as a predictor of early and middle adulthood siblings' use of relational maintenance behaviors. Communication Research Reports, 25, 155-167. doi: 10.1080/08824090802022028

Myers, S. A., Goodboy, A. K., \& Members of COMM 201. (2013). Using equity theory to explore adult siblings' use of relational maintenance behaviors and relational characteristics. Communication Research Reports, 30, 275-281. doi: $10.1080 / 08824096.2013 .836627$

Myers S. A., \& Members of COM 200. (2001). Relational maintenance behaviors in the sibling relationship. Communication Quarterly, 49, 19-34. doi: 10.1080/01463370109385612 
Myers, S. A. \& Weber, K. D. (2004). Preliminary development of a measure of sibling relational maintenance behaviors: Scale development and initial findings. Communication Quarterly, 52, 334-346. doi: 10.1080/01463370409370204

Ogolsky, B. G., \& Bowers, J. R. (2012). A meta-analytic review of relationship maintenance and its correlates. Journal of Social and Personal Relationships, 30, 343-367. doi: $10.1177 / 0265407512463338$

Punyanunt-Carter, N. M. (2008). Father-daughter relationships: Examining family communication patterns and interpersonal communication satisfaction. Communication Research Reports, 25, 23-33. doi: 10.1080/08824090701831750

Ritchie, L. D., \& Fitzpatrick, M. A. (1990). Family communication patterns: Measuring intrapersonal perceptions of interpersonal relationships. Communication Research, 17, 523-544. doi: 10.1177/009365090017004007

Roberts, A. (2003). Long-distance romantic relationships: Attachment, closeness, and satisfaction (Doctoral dissertation). Retrieved from ProQuest. AAI3124212

Samek, D. R., \& Rueter, M. A. (2011). Associations between family communication patterns, sibling closeness, and adoptive status. Journal of Marriage and Family, 73, 1015-1031. doi: $10.1111 / \mathrm{j} .1741-3737.2011 .00865 . \mathrm{x}$

Schrodt, P., \& Ledbetter, A. M. (2007). Communication processes that mediate family communication patterns and mental well-being: A mean and covariance structures analysis of young adults from divorced and non-divorced families. Human Communication Research, 33, 330-356. 
Schrodt, P., Ledbetter, A. M., \& Ohrt, J. K. (2007). Parental confirmation and affection as mediators of family communication patterns and children's mental well-being. Journal of Family Communication, 7, 23-46. doi: 10.1080/15267430709336667

Schrodt, P., Witt, P. L. \& Messersmith, A. S. (2008). A meta-analytical review of family communication patterns and their associations with information processing, behavioral, and psychosocial outcomes. Communication Monographs, 75, 248-269. doi: $10.1080 / 03637750802256318$

Shearman, S. M., \& Dumlao, R. (2008). A cross-cultural comparison of family communication patterns and conflict between young adults and parents. Journal of Family Communication, 8, 186-211. doi: 10.1080/15267430802182456

Stafford, L. (2011). Measuring relationship maintenance behaviors: Critique and development of the revised relationship maintenance behavior scale. Journal of Social and Personal Relationships, 28, 278-303. doi: 10.1177/0265407510378125

Stafford, L. \& Canary, D. J. (1991). Maintenance strategies and romantic relationship type, gender and relational characteristics. Journal of Social and Personal Relationships, 8, 217-242. doi: 10.1177/0265407591082004

Stafford, L., \& Canary, D. J. (2006). Equity and interdependence as predictors of relational maintenance strategies. The Journal of Family Communication, 6, 227-254. doi: $10.1207 / \mathrm{s} 15327698 j \mathrm{jc} 0604 \_1$

Vangelisti, A. L. (2004). Introduction. In A. L. Vangelisi (Ed.), Handbook of family communication (pp. xiii-xx). Mahwah, NJ: Lawrence Erlbaum.

White, L. (2001). Sibling relationships over the life course: A panel analysis. Journal of Marriage and Family, 63, 555-568. doi: 10.1111/j.1741-3737.2001.00555.x 
White, J. M., \& Klein, D. M. (2008). Family theories ( ${ }^{\text {rd }}$ ed.). Thousand Oaks: Sage.

Wright, K. (2004). On-line relational maintenance strategies and perceptions of partners within exclusively internet-based and primarily internet-based relationships. Communication Studies, 55, 239-253. doi: 10.1080/10510970409388617 


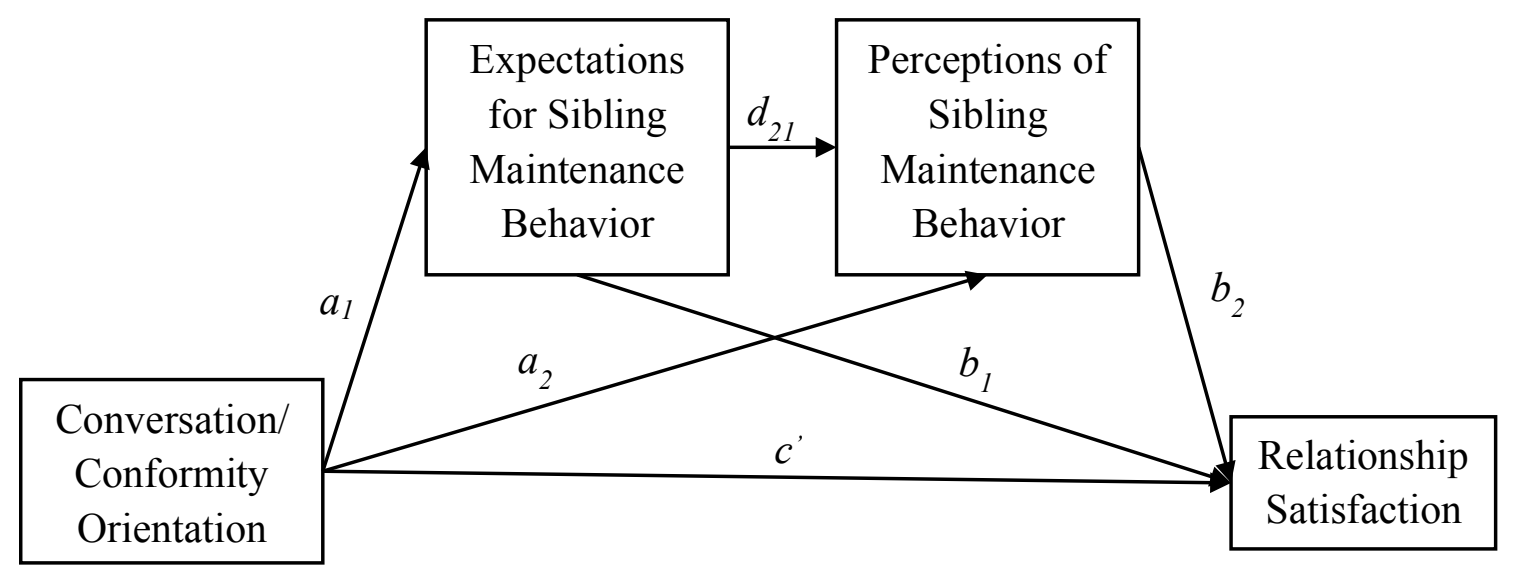

Figure 1. Proposed Mediation Model and Model Results.

Table 1. Means, Standard Deviations, Reliability, and t-test Results of Relationship Maintenance Scales

\begin{tabular}{l|lll|lll|ll}
\hline & \multicolumn{7}{|l|}{$\begin{array}{l}\text { Expectations of Sibling } \\
\text { Maintenance Behaviors }\end{array}$} & \multicolumn{4}{l|}{$\begin{array}{l}\text { Perceptions } \\
\text { Maintenance Behaviors }\end{array}$} \\
& $M$ & $S D$ & $\alpha$ & $M$ & $S D$ & $\alpha$ & $t(D F)$ & $d$ \\
\hline Positivity & 5.60 & 1.10 & .94 & 4.52 & 1.57 & .96 & $12.67(322)^{ \pm}$ & .80 \\
Openness & 4.98 & 1.32 & .92 & 3.85 & 1.57 & .93 & $13.14(322)^{ \pm}$ & .78 \\
Assurances & 5.54 & 1.26 & .88 & 4.51 & 1.69 & .91 & $11.89(322)^{ \pm}$ & .69 \\
Network & 4.99 & 1.34 & .89 & 4.12 & 1.55 & .89 & $10.37(321)^{ \pm}$ & .60 \\
Tasks & 5.62 & 1.27 & .93 & 4.53 & 1.70 & .96 & $11.23(321)^{ \pm}$ & .73 \\
\hline
\end{tabular}

Note: $\pm p<.001$ 
Table 2. Correlation Matrix

\begin{tabular}{|c|c|c|c|c|c|c|c|c|c|c|c|c|c|c|c|c|}
\hline & 1 & 2 & 3 & 4 & 5 & 6 & 7 & 8 & 9 & 10 & 11 & 12 & 13 & 14 & 15 & 16 \\
\hline 1. Conversation & $\mathrm{X}$ & & & & & & & & & & & & & & & \\
\hline 2. Conformity & $-.35^{ \pm}$ & $\mathrm{X}$ & & & & & & & & & & & & & & \\
\hline 3. Expect. Positivity & $.15^{\ddagger}$ & .03 & $\mathrm{X}$ & & & & & & & & & & & & & \\
\hline 4. Expect. Openness & $.26^{ \pm}$ & $.12 *$ & $.63^{ \pm}$ & $\mathrm{X}$ & & & & & & & & & & & & \\
\hline 5. Expect. Assurances & $.27^{ \pm}$ & -.001 & $.78^{ \pm}$ & $.75^{ \pm}$ & $\mathrm{X}$ & & & & & & & & & & & \\
\hline 6. Expect. Networks & $.26^{ \pm}$ & .002 & $.63^{ \pm}$ & $.70^{ \pm}$ & $.67^{ \pm}$ & $\mathrm{X}$ & & & & & & & & & & \\
\hline 7. Expect. Tasks & $.18^{\ddagger}$ & .01 & $.71^{ \pm}$ & $.58^{ \pm}$ & $.73^{ \pm}$ & $.65^{ \pm}$ & $\mathrm{X}$ & & & & & & & & & \\
\hline 8. Perceptions Positivity & $.30^{ \pm}$ & -.08 & $.38^{ \pm}$ & $.21^{ \pm}$ & $.36^{ \pm}$ & $.33^{ \pm}$ & $.26^{ \pm}$ & $\mathrm{X}$ & & & & & & & & \\
\hline 9. Perceptions Openness & $.36^{ \pm}$ & .03 & $.21^{ \pm}$ & $.43^{ \pm}$ & $.32^{ \pm}$ & $.34^{ \pm}$ & $.18^{ \pm}$ & $.67^{ \pm}$ & $\mathrm{X}$ & & & & & & & \\
\hline $\begin{array}{l}\text { 10. Perceptions } \\
\text { Assurances }\end{array}$ & $.32^{ \pm}$ & -.07 & $.33^{ \pm}$ & $.27^{ \pm}$ & $.47^{ \pm}$ & $.34^{ \pm}$ & $.32^{ \pm}$ & $.85^{ \pm}$ & $.72^{ \pm}$ & X & & & & & & \\
\hline $\begin{array}{l}\text { 11. Perceptions } \\
\text { Networks }\end{array}$ & $.33^{ \pm}$ & -.03 & $.28^{ \pm}$ & $.25^{ \pm}$ & $.32^{ \pm}$ & $.46^{ \pm}$ & $.25^{ \pm}$ & $.76^{ \pm}$ & $.71^{ \pm}$ & $.76^{ \pm}$ & $\mathrm{X}$ & & & & & \\
\hline 12. Perceptions Tasks & $.27^{ \pm}$ & -.08 & $.26^{ \pm}$ & $.17^{\ddagger}$ & $.30^{ \pm}$ & $.28^{ \pm}$ & $.33^{ \pm}$ & $.72^{ \pm}$ & $.55^{ \pm}$ & $.74^{ \pm}$ & $.68^{ \pm}$ & $\mathrm{X}$ & & & & \\
\hline $\begin{array}{l}\text { 13. Relationship } \\
\text { Satisfaction }\end{array}$ & $.27^{ \pm}$ & $-.12 *$ & $.34^{ \pm}$ & $.13 *$ & $.32^{ \pm}$ & $.30^{ \pm}$ & $.27^{ \pm}$ & $.77^{ \pm}$ & $.52^{ \pm}$ & $.78^{ \pm}$ & $.62^{ \pm}$ & $.67^{ \pm}$ & $\mathrm{X}$ & & & \\
\hline 14. Participant Sex & -.02 & -.10 & $.28^{ \pm}$ & $.14 *$ & $.28^{ \pm}$ & $.19^{\ddagger}$ & $.23^{ \pm}$ & .10 & -.003 & .10 & .02 & .03 & $.11 *$ & $X$ & & \\
\hline 15. Participant Age & $-.13 *$ & $-.11 *$ & -.05 & $-.17^{\dagger}$ & -.02 & $-.13 *$ & -.06 & .08 & -.05 & .04 & -.03 & .06 & .03 & .09 & $\mathrm{X}$ & \\
\hline 16. Sibling Sex & -.01 & -.07 & .06 & .004 & .05 & .07 & .09 & $.13 *$ & $.20^{ \pm}$ & $.17^{\ddagger}$ & $.25^{ \pm}$ & $.20^{ \pm}$ & $.12 *$ & .06 & .07 & $\mathrm{X}$ \\
\hline 17. Sibling Age & $-.15^{\ddagger}$ & $-.22^{ \pm}$ & -.003 & $-.14^{\ddagger}$ & .01 & $-.12 *$ & -.01 & .08 & -.10 & .04 & -.07 & .05 & .07 & $.17^{\ddagger}$ & $.83^{ \pm}$ & .05 \\
\hline
\end{tabular}

Note: $\pm p<.001 ; \ddagger p<.01 ; * p<.05$. Correlations with participant sex and sibling sex are point biserial correlations. 
Table 3. Model Results: $\mathrm{R}^{2}$ and Direct Effects

\begin{tabular}{|c|c|c|c|c|c|c|c|}
\hline & $R^{2}$ & $a_{1}$ & $a_{2}$ & $b_{1}$ & $b_{2}$ & $c^{\prime}$ & $d_{1}$ \\
\hline $\begin{array}{l}\text { Conversation } \\
\text { Model }\end{array}$ & & $b(S E)$ & $b(S E)$ & $b(S E)$ & $b(S E)$ & $b(S E)$ & $b(S E)$ \\
\hline Positivity & $.60^{ \pm}$ & $.17^{ \pm}(.05)$ & $.31^{ \pm}(.06)$ & $.06(.05)$ & $.68^{ \pm}(.04)$ & $.04(.04)$ & $.48^{ \pm}(.07)$ \\
\hline Openness & $.32^{ \pm}$ & $.33^{ \pm}(.05)$ & $.34^{ \pm}(.06)$ & $-.16^{\ddagger}(.06)$ & $.52^{ \pm}(.05)$ & $.12 *(.06)$ & $.42^{ \pm}(.06)$ \\
\hline Assurances & $.62^{ \pm}$ & $.30^{ \pm}(.05)$ & $.28^{ \pm}(.07)$ & $-.09(.05)$ & $.70^{ \pm}(.04)$ & $.03(.04)$ & $.54^{ \pm}(.07)$ \\
\hline Network & $.43^{ \pm}$ & $.28^{ \pm}(.06)$ & $.29^{ \pm}(.06)$ & $-.01(.05)$ & $.59^{ \pm}(.05)$ & $.07(.05)$ & $.45^{ \pm}(.06)$ \\
\hline Tasks & $.48^{ \pm}$ & $.22^{ \pm}(.05)$ & $.28^{ \pm}(.07)$ & $.03(.05)$ & $.55^{ \pm}(.04)$ & $.10 *(.05)$ & $.38^{ \pm}(.07)$ \\
\hline $\begin{array}{l}\text { Conformity } \\
\text { Model }\end{array}$ & $R^{2}$ & $a_{1}$ & $a_{2}$ & $b_{1}$ & $b_{2}$ & $c^{\prime}$ & $d_{1}$ \\
\hline Positivity & $.60^{ \pm}$ & $.12 *(.05)$ & $.05(.07)$ & $.06(.05)$ & $.68^{ \pm}(.04)$ & $-.05(.05)$ & $.48^{ \pm}(.07)$ \\
\hline Openness & $.32^{ \pm}$ & $.27^{ \pm}(.06)$ & $.12(.06)$ & $-.16^{\ddagger}(.06)$ & $.52^{ \pm}(.05)$ & $-.04(.06)$ & $.42^{ \pm}(.06)$ \\
\hline Assurances & $.62^{ \pm}$ & $.16^{\dagger}(.06)$ & $.04(.07)$ & $-.09(.05)$ & $.70^{ \pm}(.04)$ & $-.04(.04)$ & $.54^{ \pm}(.07)$ \\
\hline Network & $.43^{ \pm}$ & $.12^{*}(.06)$ & $.08(.06)$ & $-.01(.05)$ & $.59^{ \pm}(.05)$ & $-.03(.06)$ & $.45^{ \pm}(.06)$ \\
\hline Tasks & $.48^{ \pm}$ & $.13 *(.06)$ & $.02(.08)$ & $.03(.05)$ & $.55^{ \pm}(.04)$ & $.001(.05)$ & $.38^{ \pm}(.07)$ \\
\hline
\end{tabular}

Note: $\pm p<.001 ; \neq p<.01 ; * p<.05$. Bootstrapping $=5000 . \mathrm{R}^{2}$ reported is for relationship satisfaction. 
Table 4. Model Results: Indirect Effects and Effect Sizes.

\begin{tabular}{|c|c|c|c|c|c|c|c|c|c|c|c|c|}
\hline \multirow[b]{2}{*}{$\begin{array}{l}\text { Conversation } \\
\text { Model }\end{array}$} & \multicolumn{2}{|l|}{$a_{1} b_{1}$} & \multicolumn{2}{|c|}{$\begin{array}{l}a_{1} b_{1} \text { Effect } \\
\text { Size }\end{array}$} & \multicolumn{2}{|c|}{$a_{1} d_{1} b_{2}$} & \multicolumn{2}{|c|}{$\begin{array}{l}a_{1} d_{1} b_{2} \\
\text { Effect Size }\end{array}$} & \multicolumn{2}{|l|}{$a_{2} b_{2}$} & \multicolumn{2}{|c|}{$\begin{array}{l}a_{2} b_{2} \text { Effect } \\
\text { Size }\end{array}$} \\
\hline & $\begin{array}{l}b \\
(S E)\end{array}$ & $\begin{array}{l}95 \% \\
\mathrm{CI}\end{array}$ & $\begin{array}{l}b \\
(S E)\end{array}$ & $\begin{array}{l}95 \% \\
\mathrm{CI}\end{array}$ & $\begin{array}{l}b \\
(S E)\end{array}$ & $\begin{array}{l}95 \% \\
\text { CI }\end{array}$ & $\begin{array}{l}b \\
(S E)\end{array}$ & $\begin{array}{l}95 \% \\
\mathrm{CI}\end{array}$ & $\begin{array}{l}b \\
(S E)\end{array}$ & $\begin{array}{l}95 \% \\
\mathrm{CI}\end{array}$ & $\begin{array}{l}b \\
(S E)\end{array}$ & $\begin{array}{l}95 \% \\
\mathrm{CI}\end{array}$ \\
\hline Positivity & $\begin{array}{l}.01 \\
(.01) \\
\end{array}$ & $\begin{array}{l}-.01- \\
.04 \\
\end{array}$ & $\begin{array}{l}.01 \\
(.01) \\
\end{array}$ & $\begin{array}{l}-.01- \\
.03 \\
\end{array}$ & $\begin{array}{l}.05^{*} \\
(.02) \\
\end{array}$ & $\begin{array}{l}.02- \\
.10 \\
\end{array}$ & $\begin{array}{l}.05 \\
(.02) \\
\end{array}$ & $\begin{array}{l}.02- \\
.09 \\
\end{array}$ & $\begin{array}{l}.21^{*} \\
(.05) \\
\end{array}$ & $\begin{array}{l}.12- \\
.32 \\
\end{array}$ & $\begin{array}{l}.19 \\
(.05) \\
\end{array}$ & $\begin{array}{l}.10- \\
.28 \\
\end{array}$ \\
\hline Openness & $\begin{array}{l}-.05 * \\
(.03)\end{array}$ & $\begin{array}{l}-.11- \\
-.01 \\
\end{array}$ & $\begin{array}{l}-.05 \\
(.02)\end{array}$ & $\begin{array}{l}-.10- \\
-.01 \\
\end{array}$ & $\begin{array}{l}.07 * \\
(.02) \\
\end{array}$ & $\begin{array}{l}.04- \\
.12 \\
\end{array}$ & $\begin{array}{l}.06 \\
(.02) \\
\end{array}$ & $\begin{array}{l}.03- \\
.10 \\
\end{array}$ & $\begin{array}{l}.17^{*} \\
(.04) \\
\end{array}$ & $\begin{array}{l}.10- \\
.27 \\
\end{array}$ & $\begin{array}{l}.16 \\
(.04) \\
\end{array}$ & $\begin{array}{l}.09- \\
.24 \\
\end{array}$ \\
\hline Assurances & $\begin{array}{l}-.03 \\
(.02) \\
\end{array}$ & $\begin{array}{l}-.07- \\
.01 \\
\end{array}$ & $\begin{array}{l}-.02 \\
(.02)\end{array}$ & $\begin{array}{l}-.06- \\
.001 \\
\end{array}$ & $\begin{array}{l}.11^{*} \\
(.03) \\
\end{array}$ & $\begin{array}{l}.07- \\
.18 \\
\end{array}$ & $\begin{array}{l}.10 \\
(.03) \\
\end{array}$ & $\begin{array}{l}.06- \\
.16 \\
\end{array}$ & $\begin{array}{l}.20 * \\
(.06) \\
\end{array}$ & $\begin{array}{l}.09- \\
.32 \\
\end{array}$ & $\begin{array}{l}.17 \\
(.05) \\
\end{array}$ & $\begin{array}{l}.08- \\
.28 \\
\end{array}$ \\
\hline Network & $\begin{array}{l}-.002 \\
(.02)\end{array}$ & $\begin{array}{l}-.04- \\
.04\end{array}$ & $\begin{array}{l}-.002 \\
(.02)\end{array}$ & $\begin{array}{l}-.04- \\
.03\end{array}$ & $\begin{array}{l}.08^{*} \\
(.02) \\
\end{array}$ & $\begin{array}{l}.04- \\
.13 \\
\end{array}$ & $\begin{array}{l}.07 \\
(.02) \\
\end{array}$ & $\begin{array}{l}.04- \\
.11 \\
\end{array}$ & $\begin{array}{l}.17^{*} \\
(.05)\end{array}$ & $\begin{array}{l}.07- \\
.27\end{array}$ & $\begin{array}{l}.15 \\
(.04) \\
\end{array}$ & $\begin{array}{l}.07- \\
.24\end{array}$ \\
\hline Tasks & $\begin{array}{l}.01 \\
(.01)\end{array}$ & $\begin{array}{l}-.02- \\
.03\end{array}$ & $\begin{array}{l}.005 \\
(.01)\end{array}$ & $\begin{array}{l}-.01- \\
.03\end{array}$ & $\begin{array}{l}.05^{*} \\
(.02)\end{array}$ & $\begin{array}{l}.02- \\
.08\end{array}$ & $\begin{array}{l}.04 \\
(.01)\end{array}$ & $\begin{array}{l}.02- \\
.07\end{array}$ & $\begin{array}{l}.16^{*} \\
(.05) \\
\end{array}$ & $\begin{array}{l}.07- \\
.24\end{array}$ & $\begin{array}{l}.14 \\
(.04)\end{array}$ & $\begin{array}{l}.06- \\
.22\end{array}$ \\
\hline $\begin{array}{l}\text { Conformity } \\
\text { Model }\end{array}$ & $a_{1} b_{1}$ & & $\begin{array}{l}a_{1} b_{1} b \\
\text { Size }\end{array}$ & ffect & $\overline{a_{1} d_{1}}$ & & $\begin{array}{l}a_{1} d_{1} \\
\text { Effec }\end{array}$ & Size & $\overline{a_{2} b_{2}}$ & & $\begin{array}{l}a_{2} b_{2} \\
\text { Size } \\
\end{array}$ & ffect \\
\hline Positivity & $\begin{array}{l}.01 \\
(.01) \\
\end{array}$ & $\begin{array}{l}-.004 \\
-.03 \\
\end{array}$ & $\begin{array}{l}.01 \\
(.01) \\
\end{array}$ & $\begin{array}{l}.03- \\
.16 \\
\end{array}$ & $\begin{array}{l}.04^{*} \\
(.02) \\
\end{array}$ & $\begin{array}{l}.01- \\
.08 \\
\end{array}$ & $\begin{array}{l}.03 \\
(.02) \\
\end{array}$ & $\begin{array}{l}.01- \\
.07 \\
\end{array}$ & $\begin{array}{l}.04 \\
(.05) \\
\end{array}$ & $\begin{array}{l}-.06- \\
.14 \\
\end{array}$ & $\begin{array}{l}.03 \\
(.04) \\
\end{array}$ & $\begin{array}{l}.06- \\
.12 \\
\end{array}$ \\
\hline Openness & $\begin{array}{l}-.04 * \\
(.02)\end{array}$ & $\begin{array}{l}-.10- \\
-.01\end{array}$ & $\begin{array}{l}-.04 \\
(.02)\end{array}$ & $\begin{array}{l}-.08- \\
-.01\end{array}$ & $\begin{array}{l}.06^{*} \\
(.02) \\
\end{array}$ & $\begin{array}{l}.03- \\
.10\end{array}$ & $\begin{array}{l}.05 \\
(.02) \\
\end{array}$ & $\begin{array}{l}.02- \\
.09\end{array}$ & $\begin{array}{l}.06 \\
(.04)\end{array}$ & $\begin{array}{l}-.02- \\
.15\end{array}$ & $\begin{array}{l}.05 \\
(.03) \\
\end{array}$ & $\begin{array}{l}.02- \\
.12 \\
\end{array}$ \\
\hline Assurances & $\begin{array}{l}-.01 \\
(.01)\end{array}$ & $\begin{array}{l}-.04- \\
.001\end{array}$ & $\begin{array}{l}-.01 \\
(.01)\end{array}$ & $\begin{array}{l}-.04- \\
.001 \\
\end{array}$ & $\begin{array}{l}.06^{*} \\
(.03) \\
\end{array}$ & $\begin{array}{l}.02- \\
.12 \\
\end{array}$ & $\begin{array}{l}.05 \\
(.02) \\
\end{array}$ & $\begin{array}{l}.01- \\
.10 \\
\end{array}$ & $\begin{array}{l}.03 \\
(.06) \\
\end{array}$ & $\begin{array}{l}-.09- \\
.14\end{array}$ & $\begin{array}{l}.02 \\
(.05) \\
\end{array}$ & $\begin{array}{l}-.07- \\
.12 \\
\end{array}$ \\
\hline Network & $\begin{array}{l}-.001 \\
(.01)\end{array}$ & $\begin{array}{l}-.02- \\
.02 \\
\end{array}$ & $\begin{array}{l}-.001 \\
(.01)\end{array}$ & $\begin{array}{l}-.02- \\
.01 \\
\end{array}$ & $\begin{array}{l}.03 \\
(.02) \\
\end{array}$ & $\begin{array}{l}-.004 \\
-.08 \\
\end{array}$ & $\begin{array}{l}.03 \\
(.02) \\
\end{array}$ & $\begin{array}{l}-.003 \\
-.06 \\
\end{array}$ & $\begin{array}{l}.05 \\
(.05) \\
\end{array}$ & $\begin{array}{l}-.05- \\
.15\end{array}$ & $\begin{array}{l}.04 \\
(.04) \\
\end{array}$ & $\begin{array}{l}-.04 \\
.13 \\
\end{array}$ \\
\hline Tasks & $\begin{array}{l}.003 \\
(.01)\end{array}$ & $\begin{array}{l}-.01- \\
.03 \\
\end{array}$ & $\begin{array}{l}.003 \\
(.01)\end{array}$ & $\begin{array}{l}-.01- \\
.02 \\
\end{array}$ & $\begin{array}{l}.03 * \\
(.02) \\
\end{array}$ & $\begin{array}{l}.003 \\
.07 \\
\end{array}$ & $\begin{array}{l}.02 \\
(.01) \\
\end{array}$ & $\begin{array}{r}.002 \\
-.05 \\
\end{array}$ & $\begin{array}{l}.01 \\
(.05) \\
\end{array}$ & $\begin{array}{l}-.09- \\
.11 \\
\end{array}$ & $\begin{array}{l}.01 \\
(.04) \\
\end{array}$ & $\begin{array}{l}.08- \\
.09 \\
\end{array}$ \\
\hline
\end{tabular}

Note: $\pm p<.001 ; \neq p<.01 ; * p<.05$. Bootstrapping $=5000$. Effect size reported is the completely standardized effect. 